\title{
Micromechanical and In situ Shear Testing of Al-SiC Nanolaminate Composites in a Transmission Electron Microscope (TEM)
}

\author{
C. Mayer ${ }^{1}$, N. $\mathrm{Li}^{2}$, N. Mara ${ }^{2}$, and N. Chawla ${ }^{1}$ *
}

${ }^{1}$ Materials Science and Engineering, Arizona State University, Tempe, AZ 85287-6106

${ }^{2}$ Center for Integrated Nanotechnologies, Los Alamos National Laboratory, Albuquerque, NM

\author{
Submitted to: \\ Materials Science and Engineering A \\ 2014 \\ *Corresponding author: nchawla@asu.edu, 480-965-2402, \\ 501 E. Tyler Mall, ECG 303 \\ Arizona State University \\ Tempe, AZ 85287-6106
}




\begin{abstract}
Nanolaminate composites show promise as high strength and toughness materials. However, due to the limited volume of these materials, micron scale mechanical testing methods must be used to determine the properties of these films. To this end, a novel approach combining a double notch shear testing geometry and compression with a flat punch in a nanoindenter was developed to determine the mechanical properties of these films under shear loading. To further elucidate the failure mechanisms under shear loading, in situ TEM experiments were performed using a double notch geometry cut into the TEM foil. Aluminum layer thicknesses of 50nm and 100nm were used to show the effect of constraint on the deformation. Higher shear strength was observed in the $50 \mathrm{~nm}$ sample $(690 \pm 54 \mathrm{MPa})$ compared to the $100 \mathrm{~nm}$ sample $(423 \pm 28.7 \mathrm{MPa})$. Additionally, failure occurred close to the Al-SiC interface in the $50 \mathrm{~nm}$ sample as opposed to failure within the Al layer in the $100 \mathrm{~nm}$ sample.
\end{abstract}

Keywords: transmission electron microscope (TEM), focused ion beam (FIB), nanostructured materials, interface, shear testing, composites 


\section{List of Figures:}

Figure 1 TEM micrograph of layered nanostructure of these composites. Uniform gray layers are amorphous $\mathrm{SiC}$ and layers with varying contrast are crystalline $\mathrm{Al}$.

Figure 2 An outline of the milling procedure for double notch pillars. A corner is milled from the top to create a square pillar with access to the side. The notches and top are then milled from the front.

Figure 3 Details of TEM double notch specimens. A) TEM foil after being attached and thinned. B) Low magnification image showing the position of samples on TEM grid post C) Detailed view of double notch geometry. D) TEM image of gauge section before deformation.

Figure 4 Schematic of in situ TEM holder showing the basic components of the system.

Figure 5 Shear stress vs. shear strain response of double notch geometry showing higher fracture stress in $50 \mathrm{~nm} \mathrm{Al}-50 \mathrm{~nm} \mathrm{SiC} \mathrm{samples} \mathrm{compared} \mathrm{to} \mathrm{the} 100 \mathrm{~nm} \mathrm{Al}-50 \mathrm{~nm} \mathrm{SiC}$ samples.

Figure 6 Schematic of the components of the double notch geometry which contribute to the measured displacement

Figure 7 Video frames showing the progression of deformation of the $50 \mathrm{~nm} \mathrm{Al}-50 \mathrm{~nm} \mathrm{SiC}$ sample

Figure 8 TEM micrographs showing fractured in situ samples. In the $50 \mathrm{~nm} \mathrm{Al}-50 \mathrm{~nm} \mathrm{SiC} \mathrm{(a)}$ sample the crack path follows the interface the majority of the distance while in the $100 \mathrm{~nm} \mathrm{Al}-$ $50 \mathrm{~nm} \mathrm{SiC}$ sample (b) the crack is within the $\mathrm{Al}$ layer the entire length.

Figure 9 Fracture surfaces of double notch pillar showing fine roughness due to interface failure in the $\mathrm{Al}-50 \mathrm{~nm} \mathrm{SiC} \mathrm{sample} \mathrm{(a),} \mathrm{and} \mathrm{ductile} \mathrm{shearing} \mathrm{in} \mathrm{the} 100 \mathrm{~nm} \mathrm{Al}-50 \mathrm{~nm} \mathrm{SiC}$ sample (b). 


\section{Introduction}

Nanolaminate materials consist of alternating layers of dissimilar materials having an individual layer thickness on the order of tens of nanometers. Nanolaminates show promise in applications requiring excellent mechanical attributes including high strength, toughness, and wear properties [1-4], as well as biocompatibility [5] and optical properties [6]. Additionally, the properties of these films can be tailored by changing the layer thicknesses to obtain optimum properties.

Quantifying the shear strength of the interfaces in nanolaminates is a challenge. It is not practical to make bulk samples due to the size limitations of the sputtering fabrication process. With focused ion beam (FIB) milling, however, precise geometries on the micrometer scale can be machined. This capability is now being exploited for mechanical testing purposes, the most common of these techniques being micropillar compression[4, 7-11]. Other types of mechanical tests, although less common, have been implemented on the micrometer scale including tensile loading [12], cantilever beam[12, 13], and fracture toughness measurement geometries[14].

A few other methods to quantify the shear properties on the microscale have been attempted, although there are experimental issues intrinsic to these techniques. Previous work by Li et al.[15] on metal-metal nanolaminate composites utilized pillars milled with interfaces inclined $45^{\circ}$ to resolve the maximum amount of shear stress on the interface. The drawback of this geometry is that in addition to the shear stress resolved on the interface, there is also a large normal stress component superimposed on the shear stress. The in situ characterization in that work utilized pillars which were inclined relative to the flat punch. While this does generate a shear stress, there is also a large bending moment on the pillars. The use of these methods is limited to interfaces with low shear strengths relative to the normal strength so that the normal and bending stresses have a minimal effect. Other studies by Pfetzing-Micklich et al.[16] and 
Heyer et al. [17] also made shear strength measurements using a FIB milled geometry having a large beam supported on either side by a thinned region that will shear when a load is applied to the center of the beam. Although this geometry allows for a fairly homogeneous shear stress state, alignment of the indenter is critical. Any deviation of the indenter from the center of the beam would induce a bending stress and/or an unequal load distribution between the two gauge sections. Additionally, this type of geometry is not ideal for in situ TEM studies because both gauge sections cannot be easily viewed simultaneously.

The double notched interlaminar shear test involves a specimen notched on opposite sides, and loaded in compression, such that the longitudinal plane between the notches is subjected to pure shear [18-20]. This test has been used extensively in bulk fiber reinforced composites, where shear failure between plies occurred consistently [18, 19].

In this paper we report on a new micromechanical compressive double-notch shear technique for accurately quantifying shear strengths of nanolaminates. This work is centered on characterizing the interfacial shear strength in $\mathrm{Al}-\mathrm{SiC}$ nanolaminates. With the double notch geometry under a compressive load, a shear stress develops between the two notches in plane with the layers of the composite. To elucidate the failure mechanisms, double notch samples were also made on TEM foils and fractured in situ. This characterization technique allowed for the crack path to be observed in relation to the layers and individual grains.

\section{Materials and Experimental Procedure}

The Al-SiC nanolaminate samples (Figure 1) were fabricated using magnetron sputtering on a Si (100) substrate. The targets used were pure $\mathrm{Al}$ (99.99\%) and $\mathrm{SiC}$ (99.5\%) (Kurt J. Lesker, 
Clarion, PA). Prior to multilayer deposition, the $\mathrm{Al}$ and $\mathrm{SiC}$ targets were sputtered for 10 minutes at 40 and $95 \mathrm{~W}$, respectively, to remove any contamination and oxides. The deposition was carried out at 95 and $215 \mathrm{~W}$ for $\mathrm{Al}$ and $\mathrm{SiC}$ respectively to achieve a deposition rate of 7.5 $\mathrm{nm} / \mathrm{min}$. An automated routine was used to deposit alternating layers until the total multilayer thickness was approximately $15 \mu \mathrm{m}$. Two types of samples with different individual layer thicknesses were used in this study. The first sample consisted of $50 \mathrm{~nm} \mathrm{Al} \mathrm{layers} \mathrm{and} 50 \mathrm{~nm} \mathrm{SiC}$ layers, whereas the second consisted of $100 \mathrm{~nm}$ Al layers and $50 \mathrm{~nm} \mathrm{SiC}$ layers.

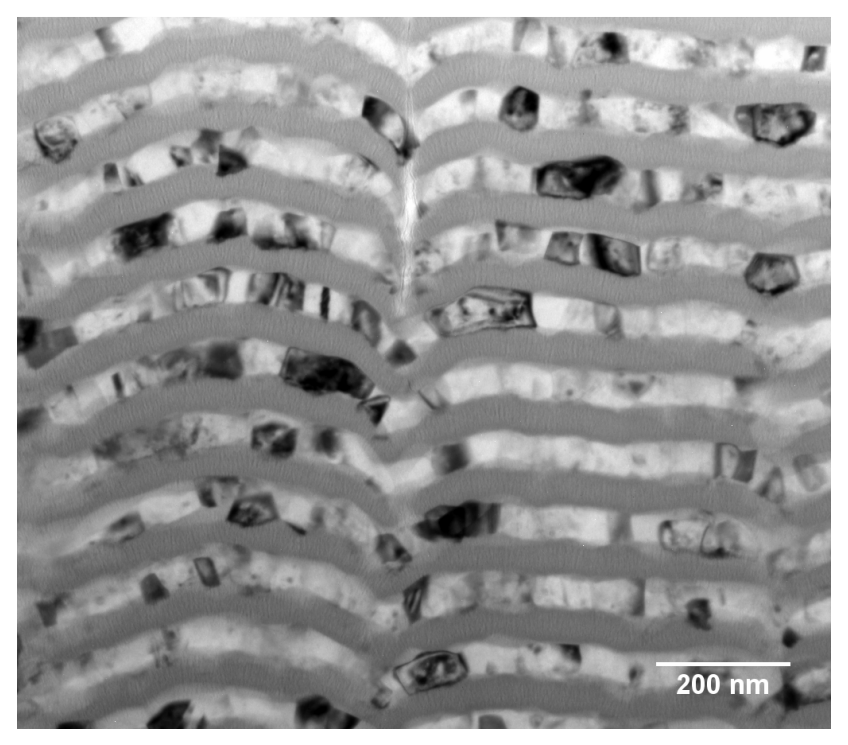

Figure 1 TEM micrograph of layered nanostructure of these composites. Uniform gray layers are amorphous $\mathrm{SiC}$ and layers with varying contrast are crystalline $\mathrm{Al}$.

Shear testing of the interface required that the films be oriented parallel to the loading axis. Therefore, the samples were mounted in epoxy edge on. Mechanical polishing to a final polish of $0.05 \mu \mathrm{m}$ colloidal silica was then carried out on 2 faces to expose a $90^{\circ}$ corner. The amount of material that needs to be removed using the FIB is dependent on the rounding at the edge. This rounding was kept to a manageable level by carefully hand polishing using $\mathrm{SiC}$ 
abrasive paper and only using the colloidal silica slurry the minimum amount of time to obtain a smooth surface finish.

Fabrication of the double notch shear pillars (Figure 2) was performed using a dual beam SEM-FIB (FEI Nova 200). Milling from two orthogonal directions was required to fabricate double notch pillars, necessitating the polished and square corner mentioned above. An ion beam current of $20 \mathrm{nA}$ was used to quickly remove material to provide sufficient clearance for the indenter tip (an approximately $25 \mu \mathrm{m}$ diameter trench) and to form a rough square pillar. To cut the notches, reduce the taper of the pillars and clean the pillar faces, decreasing ion beam currents ranging from $3 \mathrm{nA}$ to $50 \mathrm{pA}$ were used to provide increasing milling accuracy and surface quality. The notches were cut and the top was flattened by milling perpendicular to the original direction. The dimensions of the samples were 3-5 $\mu \mathrm{m}$ square cross sections with a notch separation of approximately $2 \mu \mathrm{m}$ (gauge section). The distance between the top of the pillar and the first notch was made to be larger than the gauge section to ensure that failure would occur in the gauge section. For each of the two different layer thicknesses combinations, two double notch pillars were fabricated and tested to failure. 


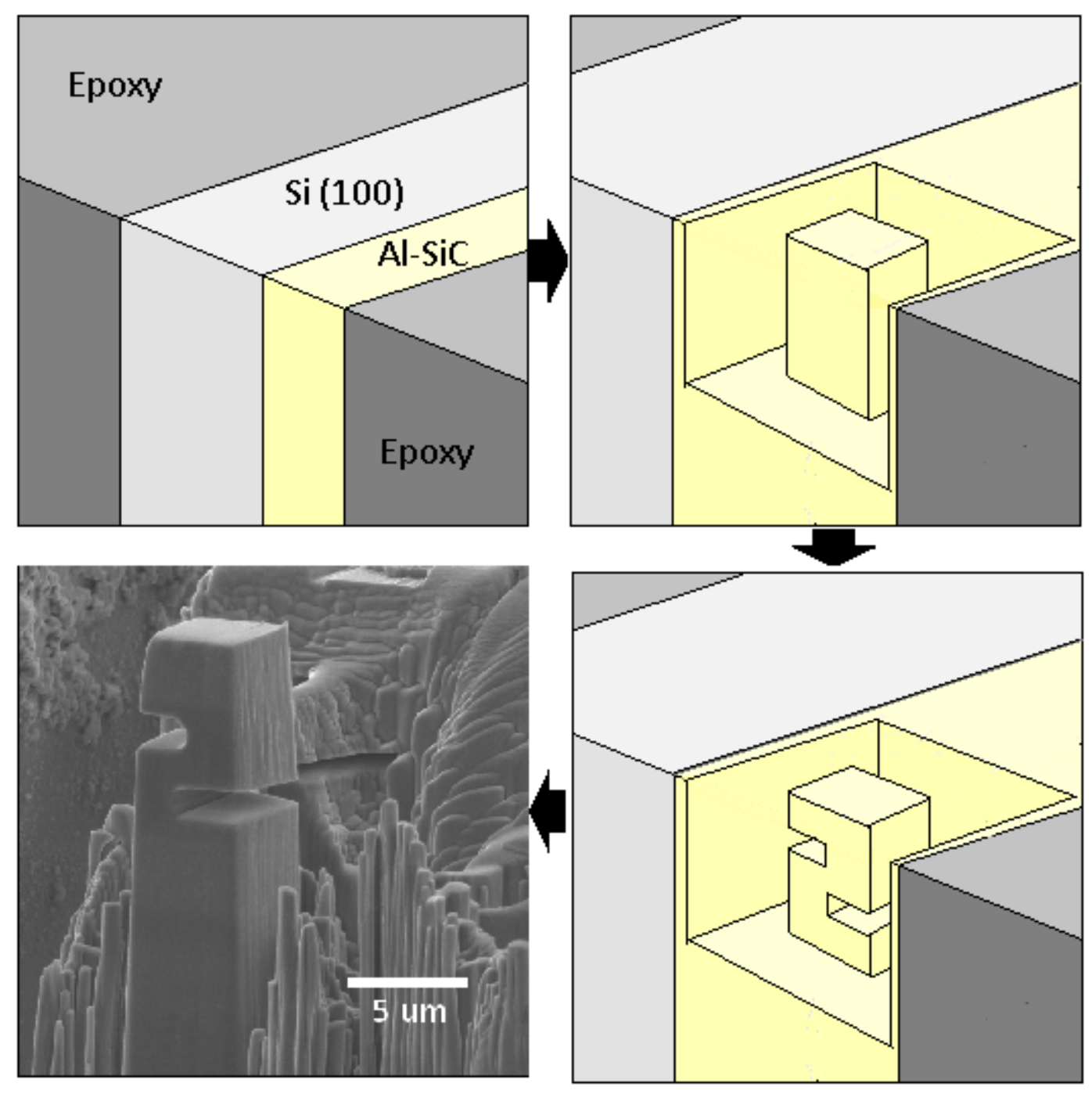

Figure 2 An outline of the milling procedure for double notch pillars. A corner is milled from the top to create a square pillar with access to the side. The notches and top are then milled from the front.

The compression of the double notch shear pillars was carried out using a commercial nanoindenter equipped with a flat punch indenter (Nanoindenter XP, Agilent). The flat punch used was diamond with a square section having side lengths of $10 \mu \mathrm{m}$. In order to preserve the fracture surface after testing, the displacement of the pillar should not exceed the size of the notches. Therefore, displacement control was used in all tests to prevent continued compression 
of the pillar following failure of the gauge section. All tests were carried out using a displacement rate of $10 \mathrm{~nm} / \mathrm{s}$ to a total depth of $1000 \mathrm{~nm}$. Following compression, the fracture surfaces of the double notch pillars were observed by scanning electron microscopy (SEM).

TEM sample preparation was carried out using a FIB lift-out procedure. The initial steps of the TEM sample preparation procedure is identical to traditional lift out method, as explained elsewhere $[21,22]$. The only deviation from traditional liftout required for this particular application was the "welding" of the foil, using platinum, to the end of the TEM grid post along the entire length of the sample as shown in Figure 3 (a) and (b). This provides greater mechanical support during straining than the traditional method of welding to the side of the grid post. After the sample was attached to the grid, the sample was thinned to approximately $200 \mathrm{~nm}$ for electron transparency. To make the faces of the foil more parallel, small tilting angles and ion beam currents as low as $10 \mathrm{pA}$ at $30 \mathrm{keV}$ were used at the final stages to reduce the taper. The TEM grids were then held perpendicular to the ion beam and the majority of the foil was removed, leaving the double notch shape (Figure 3(c)). 

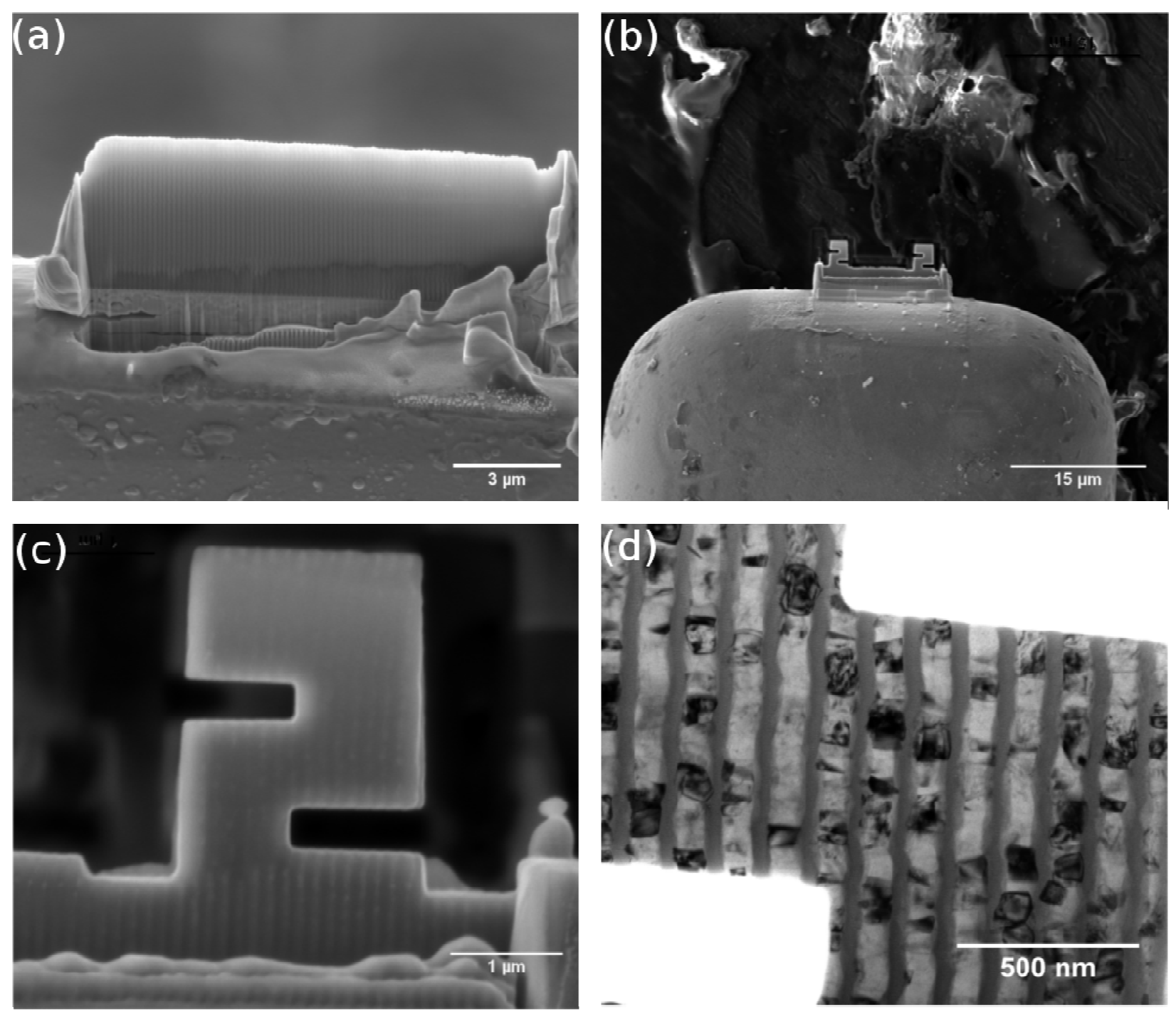

Figure 3 Details of TEM double notch specimens. A) TEM foil after being attached and thinned. B) Low magnification image showing the position of samples on TEM grid post C) Detailed view of double notch geometry. D) TEM image of gauge section before deformation.

Deformation was carried out in a FEI Tecnai F300 TEM using an in situ indentation sample holder (NanoFactory Instruments, Goteborg, Sweden). The basic components of the holder are illustrated in Figure 4. The indenter is held by spring clips to the end of a piezoelectric tube used for positioning of the indenter. The TEM grid is glued to a wire which is held in a sample holding fixture by a set screw. The microscope was operated at $300 \mathrm{keV}$ accelerating voltage in bright field TEM mode (Figure $3 \mathrm{~d}$ ). Tungsten wire sharpened using an 
electropolishing bath of $\mathrm{NaOH}$ in $\mathrm{NaNH}_{3}$ operated at $10-20 \mathrm{VAC}$ was used as an indenter for applying the load to the top of the sample. Images and video were recorded using Digital Micrograph (Gatan Inc.) during straining and after fracture.

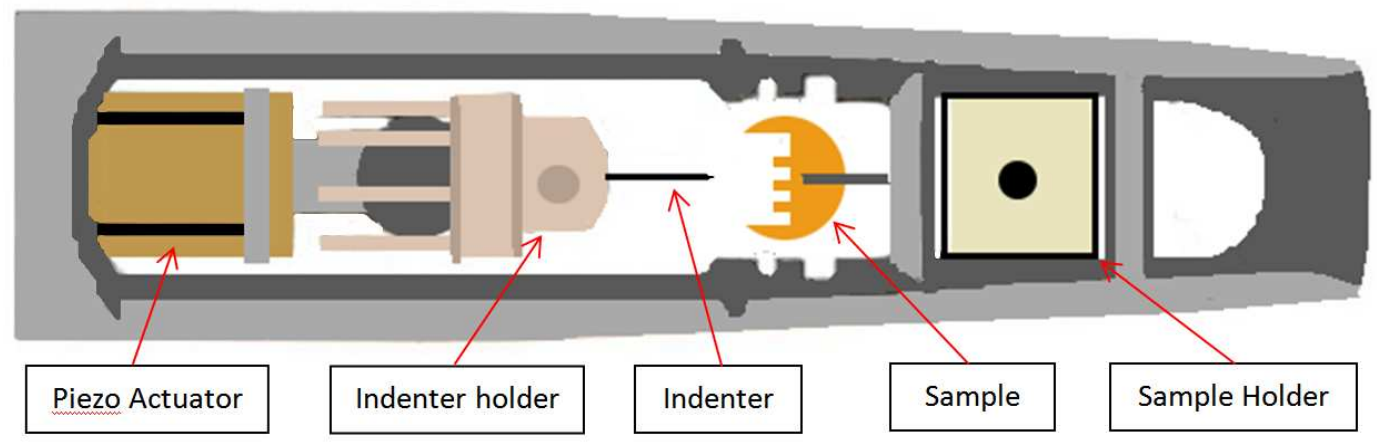

Figure 4 Schematic of in situ TEM holder showing the basic components of the system.

\section{Results and Discussion}

The shear stress vs. shear strain curves, obtained from the load displacement data for the notched pillars, is shown in Figure 5. The shear stress was calculated based on the fracture area measured after failure and the load at fracture. In order to calculate the shear strain, the displacement of only the shear section was isolated from the rest of the components of the sample. The displacements taken into consideration are shown in Figure 6. These displacements are additive, therefore, the displacement of the gauge can be written as

$$
d_{\text {gauge }}=d_{\text {total }}-d_{\text {top }}-d_{\text {bottom }}-2 d_{\text {notch }}-d_{\text {base }}-d_{\text {indenter }} \text {. }
$$




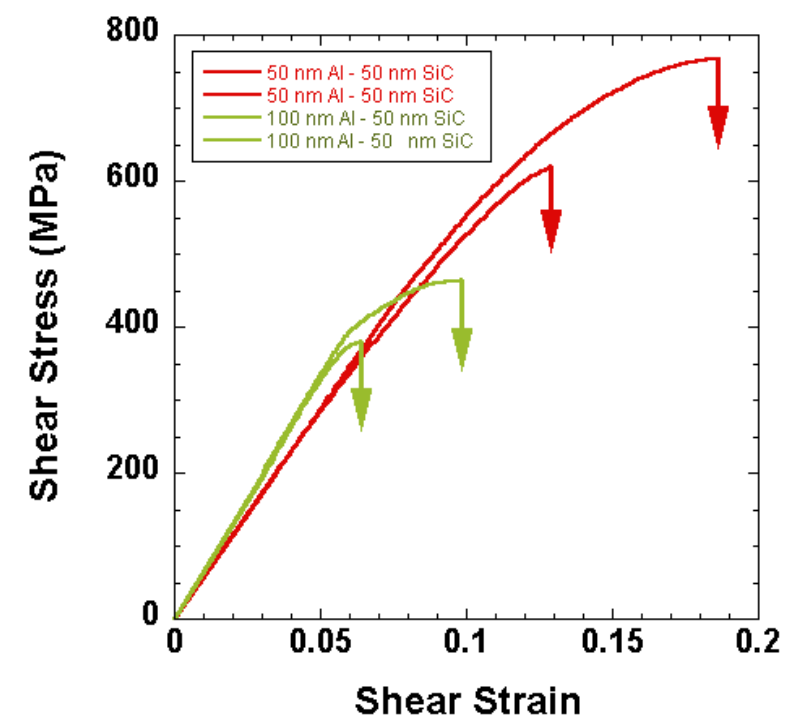

Figure 5 Shear stress vs. shear strain response of double notch geometry showing higher fracture stress in $50 \mathrm{~nm} \mathrm{Al}-50 \mathrm{~nm} \mathrm{SiC}$ samples compared to the $100 \mathrm{~nm} \mathrm{Al}-50 \mathrm{~nm} \mathrm{SiC}$ samples.

Assuming all of the components remain elastic except the gauge section, the displacements of the various components can be calculated using Hooke's Law for the top bottom and notch displacements and the Sneddon correction for the indenter and base displacements. Using Hooke's law the displacements are given by

$$
d=P h / A E,
$$

where $\mathrm{P}$ is the applied load, $\mathrm{E}$ is the modulus and $\mathrm{h}$ and $\mathrm{A}$ are the height and cross sectional area of each section respectively. The Sneddon correction accounts for the displacement of a flat punch into an elastic halfspace which is given by

$$
d=P \sqrt{\pi}\left(1-v^{2}\right) / 2 E \sqrt{A},
$$


where $\mathrm{v}$ and $\mathrm{E}$ are the Poisson's ratio and Young's modulus of the halfspace [4]. This correction may slightly underestimate the displacement due to the proximity of the pillars to the edge of the sample.

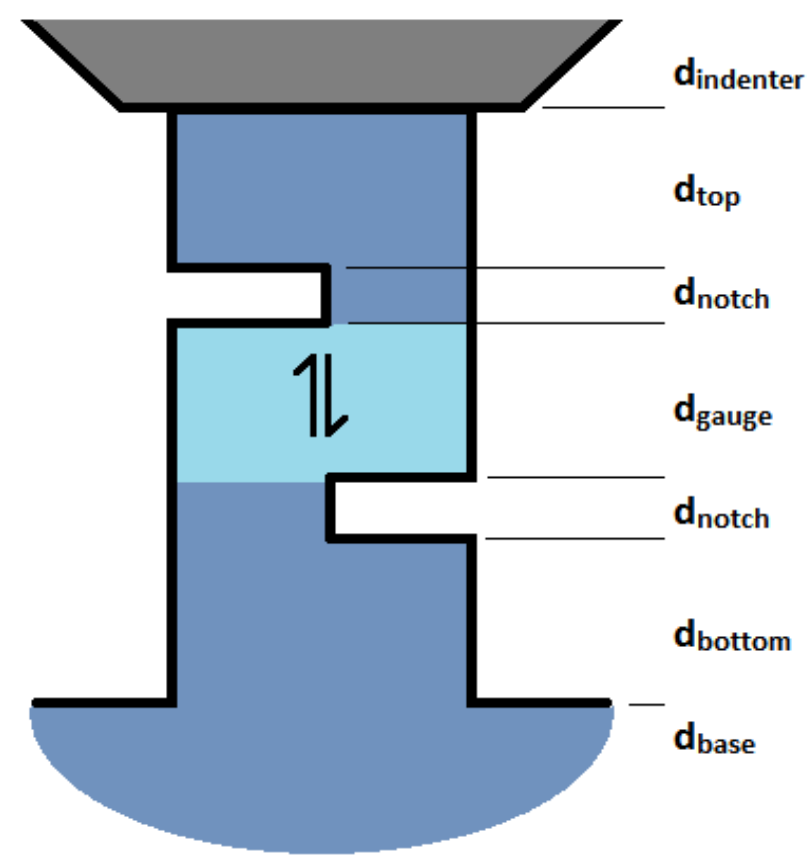

Figure 6 Schematic of the components of the double notch geometry which contribute to the measured displacement

The 50nm Al - $50 \mathrm{~nm} \mathrm{SiC}$ and $100 \mathrm{~nm} \mathrm{Al} \mathrm{-} 50 \mathrm{~nm}$ SiC samples exhibited average shear strengths of $690 \pm 54$ and $423 \pm 29 \mathrm{MPa}$, respectively. Although only two samples of each type were tested, the limited data still shows statistical significance. Assuming both samples exhibit the same variance from experimental variables and the distribution of shear strengths of these materials are normal, a Student's T test shows greater than $95 \%$ confidence that the $50 \mathrm{~nm} \mathrm{Al}-$ $50 \mathrm{~nm} \mathrm{SiC} \mathrm{samples} \mathrm{have} \mathrm{a} \mathrm{higher} \mathrm{shear} \mathrm{strength} \mathrm{than} \mathrm{the} 100 \mathrm{~nm} \mathrm{Al}-50 \mathrm{~nm} \mathrm{SiC}$.

The use of FIB milling to create small scale testing geometries has been shown to introduce microstructural changes, such as surface amorphization and ion implantation, to the surface that can affect the mechanical behavior of materials [23-25]. While these are important 
considerations for many situations, the conclusions drawn from this study are still accurate and informative. All samples were processed using identical FIB parameters; therefore relative differences in strength will remain unaffected. Additionally, TEM imaging from previous work on Al-SiC multilayers by Lotfian et al. [11] shows a surface film on FIB milled micropillars, presumably from ion beam redeposition, amorphization, or oxidation with thicknesses of approximately $5 \mathrm{~nm}$ on the aluminum and $3 \mathrm{~nm}$ on the SiC. Considering the size of the double notch pillars used in this study, this thickness of surface film would have a negligible effect on the measured mechanical response.

Geometric effects can also play a role in the material response. Due to the waviness of the layers, as seen in Figure 1, a straight notch cut through the nanolaminate sample will not fall on a single layer or interface, making the applied shear stress not on a single continuous layer or interface. Additionally, the radius of the notch corners can affect the amount of stress concentration at the top and bottom of the shear area. These effects were kept to a minimum by using the same fabrication steps for all samples. If fact, the fracture path was relatively independent of the small sample-to-sample variability of where the notch ended.

It is expected that the thinner Al layer should exhibit greater strengths due to the increase in constraint and decrease in grain size. Constraint increases the strength of the aluminum layer because it creates a triaxial tensile stress state which decreases the Von Mises effective stress in the lower stiffness aluminum layer. Hardness measurements of nanocrystaline Al made by RF sputtering show an increase in strength with decreasing grain size commensurate with the HallPetch relation over the grain sizes investigated here [26]. Since the grain size is approximately proportional to the layer thickness, the predicted increase in strength when comparing the 100 $\mathrm{nm} \mathrm{Al}$ layer to the $50 \mathrm{~nm} \mathrm{Al}$ layer is a factor of 1.41 according to the Hall-Petch relation. This is 
less than the factor of 1.6 increase seen experimentally, indicating that there is some contribution from the increased constraint of the Al layers.

Determining whether the failure occurred within the Al layer, within the SiC layer, or at the interface was not possible using traditional SEM/FIB techniques. Compositional analysis using energy dispersive spectroscopy (EDS) could not be performed because the interaction depth of the electron beam is larger than the layer thickness, causing characteristic $\mathrm{x}$-rays to be emitted from both the $\mathrm{Al}$ and $\mathrm{SiC}$ layers. Additionally, since the top portion of the pillar is not attached following fracture, only the fracture surface on the base side of the pillar was available for analysis.

Uncertainty in fracture path necessitated the use of the in situ TEM techniques. Video frames showing the progression of deformation and fracture through the $50 \mathrm{~nm} \mathrm{Al}-50 \mathrm{~nm} \mathrm{SiC}$ sample are shown in Figure 7(a-d) (Full video of the deformation is available online as supplemental material). Images of the fractured TEM samples are shown in Figure 8. In the 50 $\mathrm{nm} \mathrm{Al}-50 \mathrm{~nm} \mathrm{SiC}$ sample, the fracture path followed the Al-SiC interface for the majority of the sample but occasionally fractured through the Al layer, and then continued on the adjacent interface. In the $100 \mathrm{~nm} \mathrm{Al}-50 \mathrm{~nm} \mathrm{SiC} \mathrm{sample,} \mathrm{on} \mathrm{the} \mathrm{other} \mathrm{hand,} \mathrm{the} \mathrm{fracture} \mathrm{path} \mathrm{was} \mathrm{within}$ the $\mathrm{Al}$ layer across the whole sample, leaving the interface intact. 

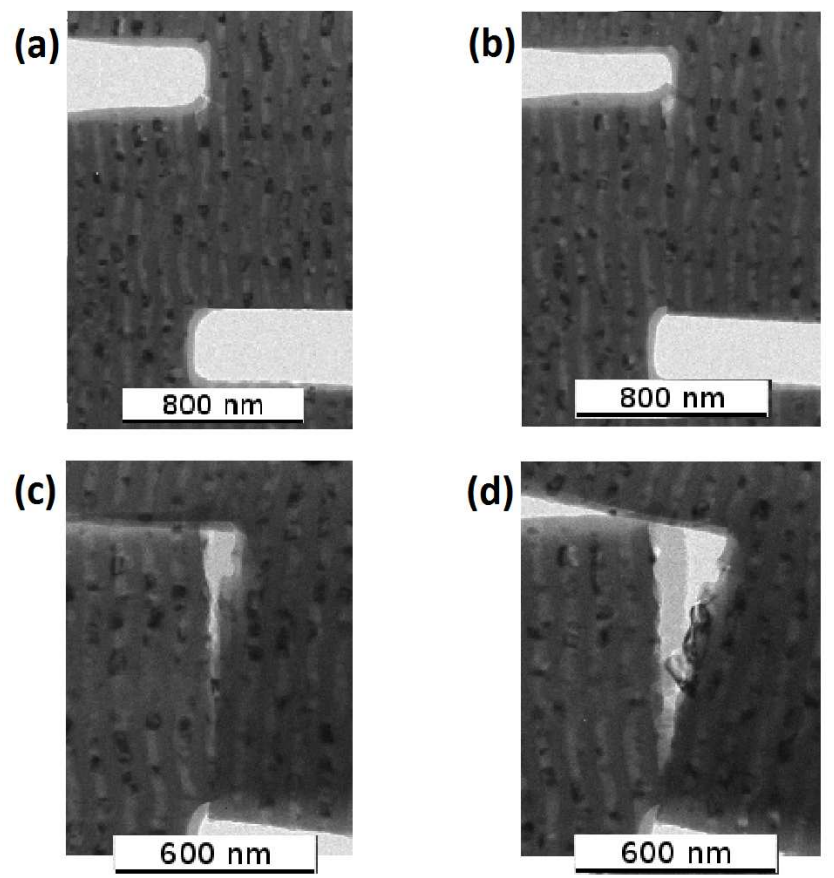

Figure 7 Video frames showing the progression of deformation of the $50 \mathrm{~nm} \mathrm{Al}-50 \mathrm{~nm} \mathrm{SiC}$ sample. Video is available online as supplemental material.
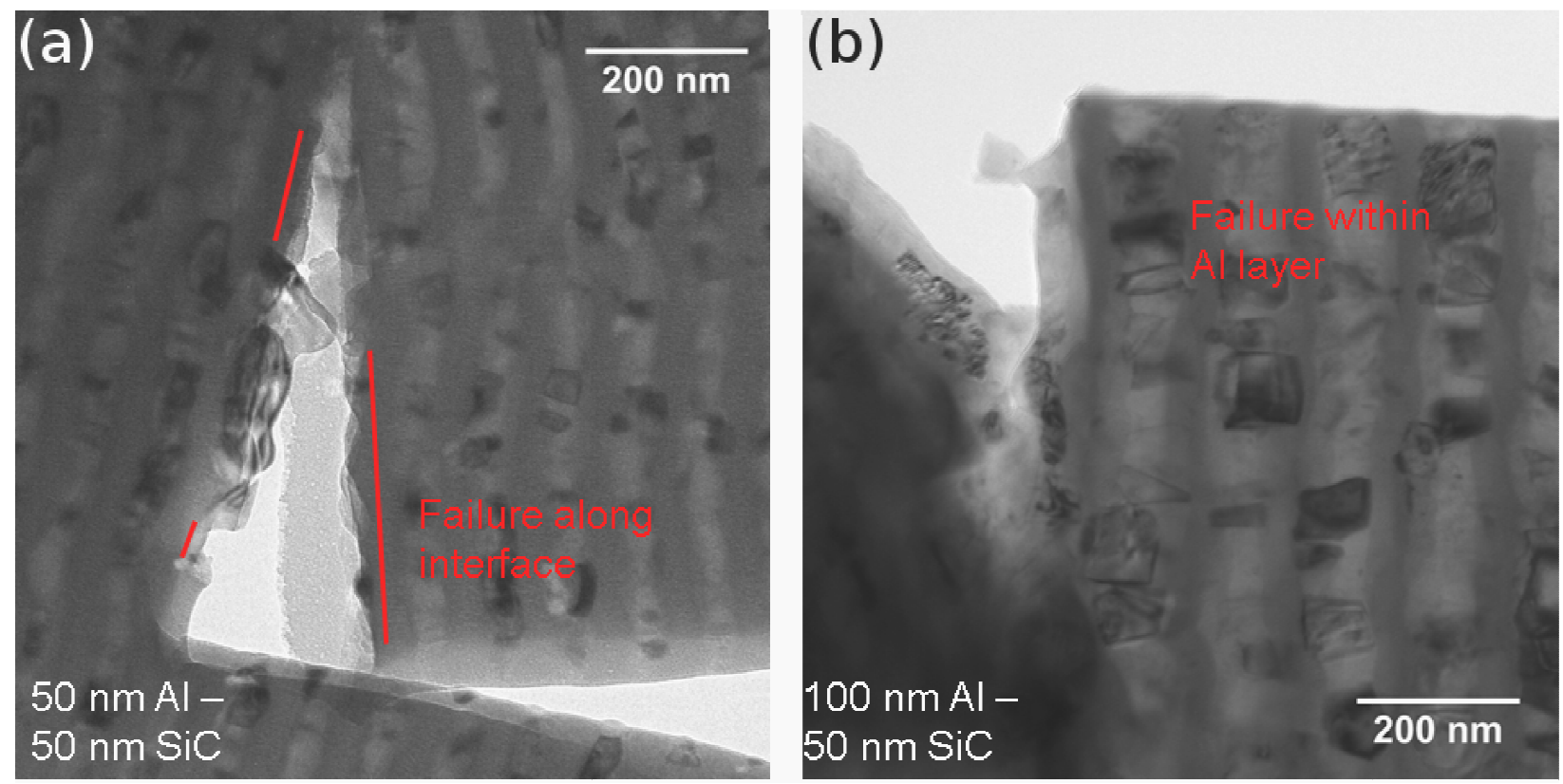

Figure 8 TEM micrographs showing fractured in situ samples. In the $50 \mathrm{~nm} \mathrm{Al}-50 \mathrm{~nm} \mathrm{SiC} \mathrm{(a)}$ sample the crack path follows the interface the majority of the distance while in the $100 \mathrm{~nm} \mathrm{Al} \mathrm{-}$ $50 \mathrm{~nm} \mathrm{SiC} \mathrm{sample} \mathrm{(b)} \mathrm{the} \mathrm{crack} \mathrm{is} \mathrm{within} \mathrm{the} \mathrm{Al} \mathrm{layer} \mathrm{the} \mathrm{entire} \mathrm{length.}$ 
. The fracture surfaces of the ex situ tests, as seen in Figure 9, show characteristically different fracture surfaces. The ductile failure surface seen in the $100 \mathrm{~nm} \mathrm{Al}-50 \mathrm{~nm} \mathrm{SiC}$ sample would be expected for failure within the aluminum layer, while a more brittle failure as seen in the $50 \mathrm{~nm} \mathrm{Al}-50 \mathrm{~nm} \mathrm{SiC}$ sample would be expected for failure at the interface. The $50 \mathrm{~nm} \mathrm{Al}-$ $50 \mathrm{~nm} \mathrm{SiC} \mathrm{sample} \mathrm{surfaces} \mathrm{show} \mathrm{fine} \mathrm{surface} \mathrm{roughness} \mathrm{and} \mathrm{occasional} \mathrm{cracking,} \mathrm{presumably} \mathrm{in}$ the adjacent $\mathrm{SiC}$ layer. The fine surface roughness is likely due to the extremely high constraint in these samples. Similar features are seen in tearing topography fracture surfaces (TTS), where the constraint in the material creates a highly triaxial state of stress, thereby limiting the size of voids that are formed and generating a surface with very fine roughness [27, 28]. The surface of the $100 \mathrm{~nm} \mathrm{Al}-50 \mathrm{~nm} \mathrm{SiC}$ shows a fracture surface with larger elongated dimples which is characteristic of greater plasticity in the aluminum layer.
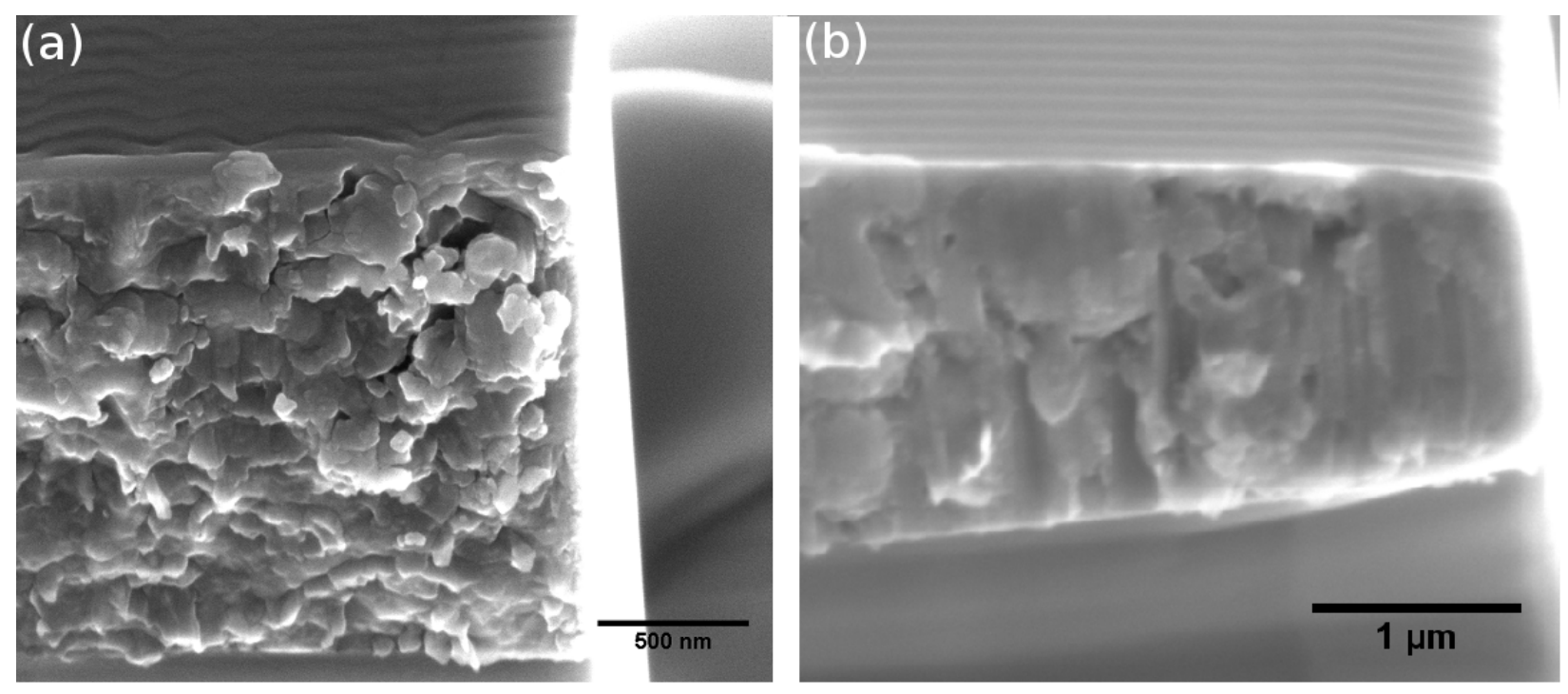

Figure 9 Fracture surfaces of double notch pillar showing fine roughness due to interface failure in the $\mathrm{Al}-50 \mathrm{~nm} \mathrm{SiC} \mathrm{sample} \mathrm{(a),} \mathrm{and} \mathrm{ductile} \mathrm{shearing} \mathrm{in} \mathrm{the} 100 \mathrm{~nm} \mathrm{Al}-50 \mathrm{~nm} \mathrm{SiC}$ sample (b). 
This gives us insight into the interface strength of these materials and the effect of constraint on the deformation behavior. Since the layers are oriented such that the shear stress is in plane with the lamina, the fracture strength is dictated by the strength of the weakest layer. The failure of the $50 \mathrm{~nm} \mathrm{Al}-50 \mathrm{~nm} \mathrm{SiC} \mathrm{TEM} \mathrm{samples} \mathrm{along} \mathrm{the} \mathrm{interface} \mathrm{shows} \mathrm{that} \mathrm{the} \mathrm{shear}$ strength of the constrained aluminum layer is greater than that of the interface, because failure takes place at the interface. Thus, the interfacial shear strength of the $50 \mathrm{~nm} \mathrm{Al}-50 \mathrm{~nm} \mathrm{SiC}$ sample as measured from the FIB'd double notch specimen is approaching $690 \pm 54 \mathrm{MPa}$. Experiments at even lower thickness are being carried out to verify the hypothesis that true failure at the interface may take place at smaller Al layer thickness. On the other hand, in the 100 $\mathrm{nm} \mathrm{Al} \mathrm{sample,} \mathrm{the} \mathrm{Al}$ layer was thicker and fracture progressed within the Al layer. Here one can see that the fracture is likely controlled by yielding of the Al layer, which results in a lower overall shear strength of $423 \pm 29 \mathrm{MPa}$. The shear strength of these materials may increase with decreasing Al layer thickness due to strengthening from constraint and decreasing grain size until it reaches a critical value where the interface is the strength limiting factor.

\section{Conclusions}

In this work, ex situ and in situ characterization of the shear deformation behavior of $\mathrm{Al}-\mathrm{SiC}$ nanolaminate composites was carried out. A novel ex situ micromechanical testing method quantified the shear strength of two layer thickness combinations which show characteristically different fracture behavior. A novel micromechanical testing method quantified both the interface shear strength and the fracture shear strength of the highly constrained $100 \mathrm{~nm} \mathrm{Al} \mathrm{layer.}$ In situ TEM shear testing was used to determine the fracture path through the composite, showing the fracture strength of the $50 \mathrm{~nm} \mathrm{Al}-50 \mathrm{~nm} \mathrm{SiC}$ samples is primarily controlled by 
interfacial shear strength while the fracture strength of the $100 \mathrm{~nm} \mathrm{Al}-50 \mathrm{~nm} \mathrm{SiC}$ samples is limited by the strength of the Al layer.

\section{Acknowledgements}

The authors would like to acknowledge the National Science Foundation Materials World Network (contract DMR-1209928, Dr. Lynnette Madsen, Program Manager) for financial support of this research and the LeRoy Erying Center for Solid State Science for the use of their microscopy facilities. This work was performed, in part, at the Center for Integrated Nanotechnologies, an Office of Science User Facility operated for the U.S. Department of Energy (DOE) Office of Science. Los Alamos National Laboratory, an affirmative action equal opportunity employer, is operated by Los Alamos National Security, LLC, for the National Nuclear Security Administration of the U.S. Department of Energy under contract DE-AC52-

06NA25396. We also thank Sudhanshu S. Singh for help with the nanoindenter, and Katie Jungjohann for help with the TEM at CINT. 


\section{References}

[1] N. Chawla, D. Singh, Y.-L. Shen, G. Tang, and K. Chawla, "Indentation mechanics and fracture behavior of metal/ceramic nanolaminate composites," Journal of Materials Science, vol. 43, pp. 4383-4390, 2008.

[2] D. Singh and N. Chawla, "Scratch resistance of al/sic metal/ceramic nanolaminates," Journal of Materials Research, vol. 27, pp. 278-283, 2012.

[3] N. A. Mara, D. Bhattacharyya, P. Dickerson, R. G. Hoagland, and A. Misra, "Deformability of ultrahigh strength 5nm cu-nb nanolayered composites," Applied Physics Letters, vol. 92, no. 23, pp. 1-3, 2008.

[4] D. Singh, N. Chawla, G. Tang, and Y.-L. Shen, "Micropillar compression of al/sic nanolaminates," Acta Materialia, vol. 58, no. 20, pp. 6628-6636, 2010.

[5] W. Li, B. Kabius, and O. Auciello, "Science and technology of biocompatible thin films for implantable biomedical devices," in Engineering in Medicine and Biology Society (EMBC), 2010 Annual International Conference of the IEEE, 2010, pp. 6237-6242.

[6] G. S. Hickey, S.-S. Lih, and T. W. Barbee, Jr., "Development of nanolaminate thin-shell mirrors," Proc. SPIE, vol. 4849, pp. 63-76, 2002.

[7] J. Williams, J. Walters, M. Wang, N. Chawla, and A. Rohatgi, "Extracting constitutive stress-strain behavior of microscopic phases by micropillar compression," JOM, vol. 65, pp. 226-233, 2013.

[8] L. Jiang and N. Chawla, "Mechanical properties of cu6sn5 intermetallic by micropillar compression testing," Scripta Materialia, vol. 63, no. 5, pp. 480-483, 2010. 
[9] J. Stewart, L. Jiang, J. Williams, and N. Chawla, "Prediction of bulk tensile behavior of dual phase stainless steels using constituent behavior from micropillar compression experiments," Materials Science and Engineering: A, vol. 534, pp. 220-227, 2012.

[10] E.-Y. Guo, H.-X. Xie, S. S. Singh, A. Kirubanandham, T. Jing, and N. Chawla, "Mechanical characterization of microconstituents in a cast duplex stainless steel by micropillar compression," Materials Science and Engineering: A, vol. 598, pp. 98 - 105, 2014.

[11] S. Lotfian, M. Rodriguez, K. Yazzie, N. Chawla, J. Llorca, and J. Molina-Aldareguia, “High temperature micropillar compression of al/sic nanolaminates," Acta Materialia, vol. 61, no. 12 , pp. $4439-4451,2013$.

[12] D. Kiener, P. Kaufmann, and A. M. Minor, "Strength, hardening, and failure observed by in situ tem tensile testing," Advanced Engineering Materials, vol. 14, no. 11, pp. 960-967, 2012. [13] D. Kupka and E. Lilleodden, "Mechanical testing of solid-solid interfaces at the microscale," Experimental Mechanics, vol. 52, pp. 649-658, 2012.

[14] M. Liu, J. Huang, Y. Fong, S. Ju, X. Du, H. Pei, and T. Nieh, “Assessing the interfacial strength of an amorphous-crystalline interface," Acta Materialia, vol. 61, no. 9, pp. 3304 - 3313, 2013.

[15] N. Li, N. Mara, J. Wang, P. Dickerson, J. Huang, and A. Misra, "Ex situ and in situ measurements of the shear strength of interfaces in metallic multilayers," Scripta Materialia, vol. 67, no. 5, pp. 479-482, 2012.

[16] J. Pfetzing-Micklich, S. Brinckmann, S. Dey, F. Otto, A. Hartmaier, and G. Eggeler, “Micro-shear deformation of pure copper," Materialwissenschaft und Werkstofftechnik, vol. 42, no. 3, pp. 219-223, 2011. 
[17] J.-K. Heyer, S. Brinckmann, J. Pfetzing-Micklich, and G. Eggeler, "Microshear deformation of gold single crystals," Acta Materialia, vol. 62, no. 0, pp. 225 - 238, 2014. [18] C. Zweben, W. Smith, and M. Wardle, "Test methods for fiber tensile strength, composite flexural modulus, and properties of fabric-reinforced laminates," in Composite materials: testing and design (fifth conference), ASTM STP, vol. 674, 1979, pp. 228-262. [19] N. Chawla, P. Liaw, E. Lara-Curzio, M. Ferber, and R. Lowden, "Effect of fiber fabric orientation on the flexural monotonic and fatigue behavior of $2 \mathrm{~d}$ woven ceramic matrix composites," Materials Science and Engineering: A, vol. 557, no. 0, pp. 77 - 83, 2012, a Celebration of Prof. K.K. Chawla's Distinguished Contributions: Fibers, Foams, and Composites.

[20] K. T. Kedward, "On the short beam test method," Fibre Science and Technology, vol. 5, no. 2, pp. 85-95, 1972.

[21] M. Lekstrom, M. A. McLachlan, S. Husain, D. W. McComb, and B. A. Shollock, "Using the in situ lift-out technique to prepare tem specimens on a single-beam fib instrument," Journal of Physics: Conference Series, vol. 126, no. 1, p. 012028, 2008.

[22] D. Tomus and H. P. Ng, "In situ lift-out dedicated techniques using fib-sem system for tem specimen preparation," Micron, vol. 44, no. 0, pp. 115 - 119, 2013.

[23] S. Shim, H. Bei, M. Miller, G. Pharr, and E. George, "Effects of focused ion beam milling on the compressive behavior of directionally solidified micropillars and the nanoindentation response of an electropolished surface," Acta Materialia, vol. 57, no. 2, pp. 503 $-510,2009$. 
[24] H. Bei, S. Shim, M. K. Miller, G. M. Pharr, and E. P. George, "Effects of focused ion beam milling on the nanomechanical behavior of a molybdenum-alloy single crystal," Applied Physics Letters, vol. 91, no. 11, p. 111915, 2007.

[25] J. A. El-Awady, C. Woodward, D. M. Dimiduk, and N. M. Ghoniem, "Effects of focused ion beam induced damage on the plasticity of micropillars," Phys. Rev. B, vol. 80, p. 104104, Sep 2009.

[26] Z. Farhat, Y. Ding, D. Northwood, and A. Alpas, "Effect of grain size on friction and wear of nanocrystalline aluminum," Materials Science and Engineering: A, vol. 206, no. 2, pp. $302-313,1996$.

[27] A. Thompson and J. Chesnutt, "Identification of a fracture mode: the tearing topography surface," Metallurgical Transactions A, vol. 10, no. 8, pp. 1193-1196, 1979.

[28] J. Williams, G. Piotrowski, R. Saha, and N. Chawla, "Effect of overaging and particle size on tensile deformation and fracture of particle-reinforced aluminum matrix composites," Metallurgical and Materials Transactions A, vol. 33, no. 12, pp. 3861-3869, 2002. 